See Article page 917.

\section{Commentary: Atrial fibrillation after cardiac surgery: Getting under the hood}

Edgar Aranda-Michel, BS, a and Ibrahim Sultan, MD ${ }^{\mathrm{a}, \mathrm{b}}$

The heart is arguably among the most complex organs by way of incorporating multiple areas of physics in its functioning. It couples fluid mechanics with tissue biomechanics, all while being synchronized by specialized and structured electrical activity. Whereas hemodynamic parameters have been used traditionally to assess heart function, there is increased research into using biomechanics and strain-specific measurements to aid in this assessment. ${ }^{1}$ Kislitsina and colleagues ${ }^{2}$ from Chicago present their work on left atrial strain and postoperative atrial fibrillation (POAF). Although development of POAF has been studied in isolated coronary artery bypass graft cohorts, ${ }^{3,4}$ there has not been a systematic application of left atrial strain measurements in this setting. The 2 interesting findings are the statistically significant differences in strain measurements between the groups that developed POAF and those that did not and the increase in the predictive ability when incorporating all these strain measurements into a logistic model.

Because this article deals with the fundamental engineering concept of strain, its important to be precise on exactly what is being measured as well as the inherent drawbacks of this metric. We can consider 2 different types of strain: absolute and relative. Absolute strain is based on a universal

\footnotetext{
From the a Division of Cardiac Surgery, Department of Cardiothoracic Surgery, University of Pittsburgh, Pittsburgh, $\mathrm{Pa}$; and ${ }^{\mathrm{b}} \mathrm{Heart}$ and Vascular Institute, University of Pittsburgh Medical Center, Pittsburgh, Pa.

Disclosures: Dr Sultan receives institutional research support from AtriCure and Medtronic. Dr Aranda-Michel reported no conflicts of interest.

The Journal policy requires editors and reviewers to disclose conflicts of interest and to decline handling or reviewing manuscripts for which they may have a conflict of interest. The editors and reviewers of this article have no conflicts of interest.

Received for publication Oct 3, 2020; revisions received Oct 3, 2020; accepted for publication Oct 5, 2020; available ahead of print Oct 10, 2020.

Address for reprints: Ibrahim Sultan, MD, Division of Cardiac Surgery, Department of Cardiothoracic Surgery, University of Pittsburgh, and Center for Thoracic Aortic Disease, the Heart and Vascular Institute, University of Pittsburgh Medical Center, 5200 Centre Ave, Suite 715, Pittsburgh, PA 15232) (E-mail: sultani@upmc.edu). J Thorac Cardiovasc Surg 2022;164:925-6 $0022-5223 / \$ 36.00$

Copyright $(2020$ by The American Association for Thoracic Surgery https://doi.org/10.1016/j.jtcvs.2020.10.009
}
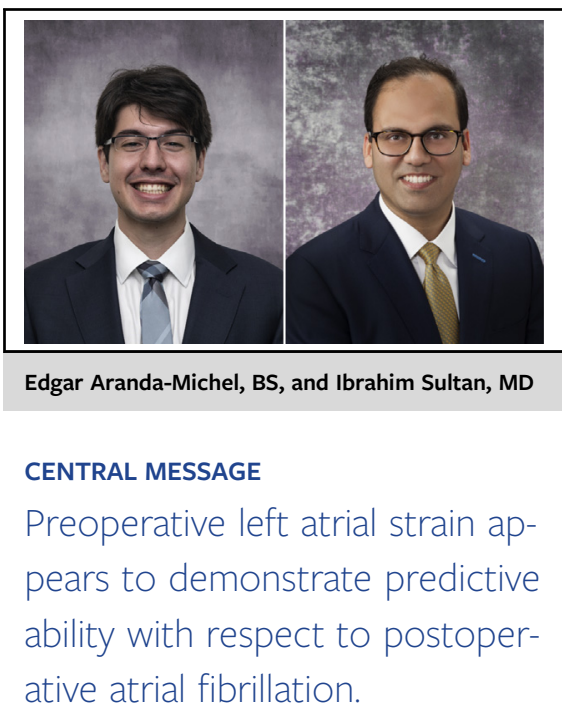

undeformed state, whereas relative strain is the change between 2 strain values. The use of speckle tracking echocardiography for strain measurements always results in relative strain, in this case the change in strain from the end diastolic filling of the left atrium (LA). This makes comparisons in relative strains between 2 samples not completely accurate because their reference values cannot be established as being equal; a 5\% strain in 2 different atria may not correspond to the same function or load on the tissue. This is particularly important because heart tissue has a hyperelastic stress strain curve, and so the relationship between deformation and pressure can differ drastically depending on the location of the reference point on the this curve. ${ }^{5}$ However, this may not be as important in this patient population because there was no statistical difference in LA volume between cohorts. Nevertheless, a way to partially account for this is to determine compliance, where changes in a volume are normalized by the change in internal pressure. Unfortunately, acquiring this hemodynamic measurement would be invasive, whereas echocardiography is relatively benign. All this is not to discredit the substantial results of this article because determining absolute strain requires advanced computational and continuum mechanics methods ${ }^{6}$ that are currently impractical to apply to a large patient population. Moreover, by just using relative strain measurements, these authors show an impressive $C$-statistic for their model.

The resulting $C$-statistics from the univariable and multivariable models are quite intriguing and hint at possible next steps in applying this method on a larger scale. The authors found that on univariable regression, all LA strain 
measurements were significant predictors for the development of POAF. However, when applied in multivariable models, none of the strain measurements gained significance. Yet, there was a large increase in the $C$-statistic going from a model that did not include any strain measurements to those that did; clearly the strain information is improving prediction. A reason behind this discrepancy could be that all the strain measurements are not in isolation from one another. Through complex biomechanics, 1 strain measurement gives rise to another. This explains why they were all individually significant on univariable analysis but not on multivariable analysis. This is further underscored by all the strain values being statistically different between the cohorts. Promisingly, the smallest change in the $C$-statistic going from univariable to the cross-validated multivariable occurs with the LA pump strain and LA peak reservoir strain. This suggests that in this study, these 2 strain values influenced the model the best and should be examined in isolation on further research.

These authors put forth a compelling article that exemplifies the benefits of applying biomechanics to cardiac surgery outcomes. The next breakthrough in cardiac surgery will be routine and established utilization of cardiac biomechanics in all aspects of patient care and this article is an important piece of that journey.

\section{References}

1. Smiseth OA, Torp H, Opdahl A, Haugaa KH, Urheim S. Myocardial strain imaging: how useful is it in clinical decision making? Eur Heart J. 2016;37: 1196-207.

2. Kislitsina JLC, Shah SJ, Malaisrie C, Kruse J, Liu M, Andrei A-C, et al. Preoperative left atrial strain abnormalities are associated with the development of postoperative atrial fibrillation following isolated coronary artery bypass surgery. $J$ Thorac Cardiovasc Surg. 2022;164:917-24.

3. Mulukutla SR, Gleason TG, Sharbaugh M, Sultan I, Marroquin OC, Thoma F, et al. Coronary bypass versus percutaneous revascularization in multivessel coronary artery disease. Ann Thorac Surg. 2019;108:474-80.

4. Bianco V, Kilic A, Gleason TG, Aranda-Michel E, Wang Y, Navid F, et al. Timing of coronary artery bypass grafting after acute myocardial infarction may not influence mortality and readmissions. J Thorac Cardiovasc Surg. 2021;161: 2056-64.e4.

5. Augustin CM, Fastl TE, Neic A, Bellini C, Whitaker J, Rajani R, et al. The impact of wall thickness and curvature on wall stress in patient-specific electromechanical models of the left atrium. Biomech Model Mechanobiol. 2020;19:1015-34.

6. Krishnamurthy A, Villongco CT, Chuang J, Frank LR, Nigam V, Belezzuoli E, et al. Patient-specific models of cardiac biomechanics. J Comput Phys. 2013; 244:4-21.

\section{Commentary: POAF goes POOF!}

\begin{abstract}
Alden H. Harken, MD
Until recently, most of us appreciated postoperative atrial fibrillation (POAF), especially in routine, otherwise healthy patients undergoing coronary artery bypass grafting (CABG), as an irritating but otherwise insignificant stumble. We recognize that POAF has the most common complications associated with cardiac surgery, but it was pretty easy to treat and we could convince our patients and their families that POAF was no big deal. Then, several huge studies-involving almost 10,000 patients-identified an approximately $50 \%$ increase in mortality associated with
\end{abstract}

From the University of California San Francisco-East Bay (retired), Alamo, Calif. Disclosures: The author reported no conflicts of interest.

The Journal policy requires editors and reviewers to disclose conflicts of interest and to decline handling or reviewing manuscripts for which they may have a conflict of interest. The editors and reviewers of this article have no conflicts of interest.

Received for publication Oct 1, 2020; revisions received Oct 1, 2020; accepted for publication Oct 1, 2020; available ahead of print Oct 9, 2020.

Address for reprints: Alden H. Harken, MD, 1565 Alamo Way, Alamo, CA 94595 (E-mail: alden.harken68@gmail.com).

J Thorac Cardiovasc Surg 2022;164:926-7 $0022-5223 / \$ 36.00$

Copyright $₫ 2020$ Published by Elsevier Inc. on behalf of The American Association for Thoracic Surgery

https://doi.org/10.1016/j.jtcvs.2020.10.005

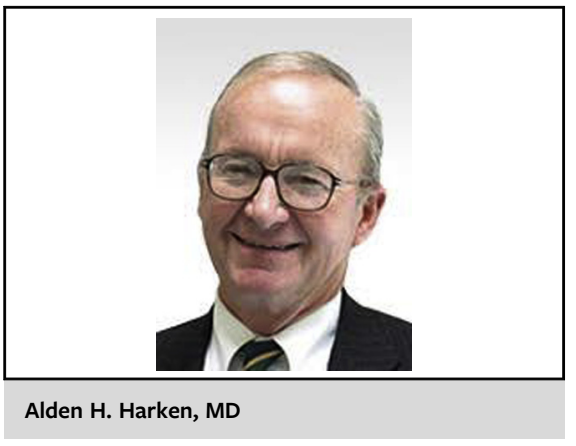

CENTRAL MESSAGE

Incorporating calculated left atrial strain into a patient's perioperative rhythm prophylaxis program might preclude nontherapeutic antidysrhythmic therapy.

POAF. That is a $50 \%$ increase in a gratifyingly small elective CABG mortality, but POAF was also linked to an increase in length of patient stay and hospital cost. This irritant caught our attention. We were successful in 